\title{
Interleukin-21 reduces Listeria monocytogenes secondary infection via CD8+ effector memory T cells
}

\section{Md. Yeashin Gazi}

Yamagata Daigaku Igakubu Daigakuin Igakukei Kenkyuka

\section{Yuji Takeda}

Yamagata Daigaku Igakubu Daigakuin Igakukei Kenkyuka

\section{Hidetoshi Nara}

Yamagata Daigaku Igakubu Daigakuin Igakukei Kenkyuka

\section{Akemi Araki}

Yamagata Daigaku Igakubu Daigakuin Igakukei Kenkyuka

\section{Nobuhito Nemoto}

Yamagata Daigaku Igakubu Daigakuin Igakukei Kenkyuka

Hironobu Asao ( $\nabla$ asao-h@med.id.yamagata-u.ac.jp )

Yamagata Daigaku Igakubu Daigakuin Igakukei Kenkyuka https://orcid.org/0000-0002-1051-4799

\section{Research article}

Keywords: challenge infection, effector memory T cells, IL-21, IL-21 isoform, Listeria monocytogenes

Posted Date: July 29th, 2020

DOI: https://doi.org/10.21203/rs.3.rs-41839/v1

License: (1) This work is licensed under a Creative Commons Attribution 4.0 International License. Read Full License 


\section{Abstract}

Background/Purpose: Interleukin-21 (IL-21), which is a member of the common $y$-chain cytokine family, is mainly produced by $\mathrm{CD} 4^{+} \mathrm{T}$ cells and has broad impact on immune responses. IL-21 isoform is a splicing variant of IL-21 and is functionally similar to conventional IL-21. We established IL-21 isoform transgenic (IL-21isoTg) mouse, which constitutively expresses IL-21 isoform specifically in T cells. IL-21isoTg mouse possesses high amount of $\mathrm{CD}^{+} \mathrm{T}$ cells in normal physiological condition. The purpose of this study is to determine whether $\mathrm{CD} 8^{+} \mathrm{T}$ cells in the IL-21isoTg mouse work against intracellular bacteria infection.

Methods: Wild type (WT) and IL-21 isoTg mouse are orally inoculated Listeria monocytogenes (L. monocytogenes) on day 0 , and 15 days after primary infection. Bacterial load in each organs, and $\mathrm{T}$ cell responses are analyzed.

Results: IL-21isoTg and wild type (WT) mouse had similar bacterial load after L. monocytogenes primary infection. On the other hand, after secondary challenge infection, IL-21 isoTg mouse exhibited reduced bacterial load in some organs compared to WT. Analysis of T cell response after primary infection showed that IL-21isoTg mouse induced higher levels of CD8 ${ }^{+}$effector memory $T\left(T_{E M}\right)$ cells than WT.

Conclusion: IL-21-induced $\mathrm{CD} 8^{+} \mathrm{T}_{\mathrm{EM}}$ cells might eventually reduce the bacterial load in organs after secondary challenge infection in IL-21 isoTg mouse. To the best of our knowledge, this is the first study to show that IL-21 is a pivotal factor involved in eliminating intracellular bacteria, probably through $\mathrm{CD}^{+}$ $\mathrm{T}_{\mathrm{EM}}$ cells.

\section{Background}

Interleukin 21 (IL-21) is a member of the common y-chain cytokine family, comprising of IL-2, IL-4, IL-7, IL9, and IL-15. This proinflammatory cytokine is produced by activated CD4 ${ }^{+} \mathrm{T}$ cells, in particular follicular helper T cells, Th17, and activated NKT cells (Spolski 2014). IL-21 acts on various targets of the immune system, including T cells, B cells, dendritic cells, and NK cells (Parrish-Novak 2000; Spolski 2008). IL-21 enhances the proliferation and function of $\mathrm{CD}^{+} \mathrm{T}$ cells in conjunction with IL-15 (Zeng 2005), increases the antitumor activity of $\mathrm{CD}^{+} \mathrm{T}$ cells (Zeng 2005; Hinrichs 2008), facilitates the maturation of memory $\mathrm{CD}^{+} \mathrm{T}$ cells by the activation of STAT3 (Cui 2011), and controls chronic lymphocytic choriomeningitis viral infection in mice by triggering polyfunctional effector $\mathrm{CD}^{+} \mathrm{T}$ cells (Elsaesser 2009; Fröhlich 2009; Yi 2009).

$\mathrm{CD}^{+} \mathrm{T}$ cell development and response are triggered by the recognition of presented antigen in addition to costimulatory signals and cytokines. A large number of $\mathrm{CD} 8^{+}$effector $\mathrm{T}$ cells can be generated following the activation of naïve $\mathrm{CD} 8^{+} \mathrm{T}$ cells, and these responses operate to eliminate target cells; however, a large percentage of these cells are prone to apoptosis and lack the self-renewal capacity necessary to form the memory pool (Kaech 2012). On the other hand, CD8 ${ }^{+}$memory T cells are maintained over time 
following the peak of the response and contribute to long-lived immunity (Mueller 2013). The memory cells can be subdivided into central memory $T\left(T_{C M}\right)$ cell and effector memory $T\left(T_{E M}\right)$ cell subsets (Sallusto 1999). $T_{C M}$ cells reside in lymphoid tissues and mount rapid proliferative recall responses that help to amplify and replenish the response during secondary antigenic exposures (Wherry 2003; Masopust 2001). $T_{E M}$ cells can migrate to nonlymphoid organs and immediately produce effector cytokines and cytotoxic proteins following reactivation but are less proliferative (Hansen 2011; Hansen 2013; Hansen 2009). The ability of $T_{E M}$ cells may be vital for the control of certain chronic pathogens, such as SIV and malaria, before the infection is fully established (Reyes-Sandoval 2011; Ariotti 2014; Gebhardt 2009; lijima 2014).

The major site of microbial entry, intestinal mucosa and mucosal tissues are able to quickly respond to infections by providing the highly controlled and strong immunity. Providing precise $T$ cell response is ultimate goal to put an end for most intracellular pathogenic infections. Like other intracellular bacterial infections, Listeria monocytogenes (L. monocytogenes) also required an accurate and precise T cell responses to provide protective function and eliminate infected cells. Oral infection of $L$. monocytogenes enhances intestinal resident memory $\mathrm{CD} 8^{+} \mathrm{T}$ cells and impart crucial protective function. After infection, activated T cells migrate to peripheral tissues and played a role to eliminate pathogens completely (Sheridan 2014).

Our group previously found an IL-21 splicing variant transcript, IL-21 isoform, which is present in humans and mice (Rahman 2007). This isoform activates STAT1 and STAT3 similar to conventional IL-21. However, this isoform is present on the cell surface and is secreted into the culture supernatant at very low levels (Rahman 2007; Nara 2013). Since IL-21 transgenic mouse could not be established, we have established an IL-21 isoform transgenic (IL-21 isoTg) mouse that expresses mouse IL-21 isoform in T cells to evaluate the function of IL-21 in vivo (Araki 2013). IL-21 isoTg mouse was shown to possess high amount of $\mathrm{CD}^{+} \mathrm{T}$ cells in normal physiological condition (Araki 2013). In this study, we infected the IL21 isoTg mouse with the intracellular bacteria $L$. monocytogenes by oral route to investigate the function of IL-21 and IL-21-induced CD8 ${ }^{+} \mathrm{T}$ cells in intracellular pathogen control in vivo.

\section{Methods}

\section{Mice}

C57BL/6J mice were purchased from CREA, Japan. IL-21isoTg mice were generated as described previously (Araki 2013). Mice were maintained in a 12-h light/dark cycle under specific pathogen-free conditions and had ad libitum access to a standard diet and water until reaching the desired age (6-10 weeks). All mice experiments were performed in accordance with the guidelines of the Laboratory Animal Center of the Yamagata University Faculty of Medicine and were approved by the animal experiment committee of the Yamagata University Faculty of Medicine (approval number: 31005).

\section{Bacteria and bacterial stock preparation}


L. monocytogenes strain EGDe expressing mutant internalin A (S129N and Y369S) (Lmo-InIA ${ }^{\mathrm{m}}$ ) was a kind gift from Prof. Dr. D. Heinz and Dr. Joop van den Heuvel (2007). To prepare the stock, bacteria were grown in Tryptic Soy broth for 17 hours. The bacteria were stored at $-80^{\circ} \mathrm{C}$ after the OD reached approximately 1.0. The bacteria were then grown on tryptic soy agar plate and the bacterial colonies were counted 24-48 hours after incubation. The desired inoculum of bacterial strain was mixed with PBS containing $\mathrm{CaCO}_{3}$ (2007).

\section{L. monocytogenes infection and determination of bacterial load in the organs}

Mice, which were starved overnight and provided only with water, were intragastrically inoculated with the bacterial suspension using a 21-gauge feeding needle attached to a $1 \mathrm{~mL}$ syringe. Wild type (WT) and transgenic $(\mathrm{Tg})$ mice were inoculated with a sublethal dose of bacteria $\left(5 \times 10^{11} \mathrm{CFU}\right)$ for primary infection. After 15 days of primary infection, mice were inoculated with bacteria $\left(1 \times 10^{12} \mathrm{CFU}\right)$ for secondary challenge infection. After 3 days of infection, mice were euthanized by deep anesthesia with $5 \% \mathrm{vol} / \mathrm{vol}$ isoflurane inhalation to collect spleen, liver, mesenteric lymph nodes ( $\mathrm{mLN}$ ) and small intestine. The small intestines were removed and incubated in PBS supplemented with $100 \mu \mathrm{g} / \mathrm{mL}$ gentamicin sulfate, to kill extracellular bacteria, for 2 hours at room temperature. Other organs were dissected under sterile conditions. Organs were homogenized and serial dilutions of the homogenates were plated onto tryptic soy agar plates. After 24-36 hours of incubation, colony numbers were counted to determine the bacterial load in each organ.

\section{Cell staining and flow cytometry analysis}

Single-cell suspensions of spleen and $\mathrm{mLN}$ were prepared using a glass homogenizer before and after 10 days of primary infection. RBCs in the spleen cells were lysed and then, spleen and mLN cells were washed twice with PBS. Spleen and mLN cells were incubated with V450-anti-mouse CD3 (BD Biosciences, Clone \# 17A2), FITC-anti-mouse CD4 (BioLegend, Clone \# RM4-5), PE/Cy7-anti-mouse CD8a (BioLegend, Clone \# 53-67), APC-anti-mouse CD62L (BioLegend, Clone \# 104411) and PE-anti-mouse CD44 (BD Pharmingen, Clone \# IM7) antibodies on ice for 30 minutes in $3 \%$ FCS-PBS with $0.02 \% \mathrm{NaN}_{3}$.

Cells were washed with the same buffer and then analyzed by FACSCanto II flow cytometer (BD Biosciences). Data were analyzed by FlowJo software (version 7.6.1, Tree Star).

\section{Statistical Analysis}

The differences between the bacterial loads in the organs of WT and IL-21isoTg mice were analyzed by two-way ANOVA with Bonferroni post hoc test. The statistical significance of cell numbers in the organs of infected and non-infected mice was analyzed by one-way ANOVA with Tukey post hoc test. Data were analyzed using the GraphPad Prism Software version 5.03 (GraphPad Software, San Diego, CA, USA). Results with $\mathrm{p}<0.05$ were considered as statistically significant.

\section{Results}

\section{Bacterial load was reduced in IL-21isoTg mice after secondary challenge infection}


IL-21 isoTg mice showed higher percentage of $\mathrm{CD}^{+} \mathrm{T}$ cells in spleen, peripheral $\mathrm{LN}$, and $\mathrm{mLN}$ than WT mice in normal physiological conditions (Araki 2013). $C D 8^{+} \mathrm{T}$ cells are important for removing intracellular microorganisms such as $L$. monocytogenes and protecting our body. To test the function of excessive, self-producing CD $8^{+} \mathrm{T}$ cells, we infected WT and IL-21isoTg mice with $L$. monocytogenes orally. After 3 days of infection, mice were sacrificed and the bacterial loads of the spleen, liver, and $\mathrm{mLN}$ were evaluated. There were no differences in bacterial load in these organs between WT and IL-21isoTg mice (Fig. 1a). This result indicates that the self-producing CD8 ${ }^{+} \mathrm{T}$ cells in IL-21 isoTg mice are not effective in controlling L. monocytogenes during primary infection. After 15 days of primary infection, we challenged the mice with L. monocytogenes. In secondary infection, the IL-21 isoTg mice exhibited significantly reduced bacterial load in these organs compared to WT mice (Fig. 1b).

\section{$\mathrm{CD}^{+} \mathrm{T}_{\mathrm{EM}}$ cells are increased after $\mathrm{L}$. monocytogenes infection in IL-21 isoTg mice}

Before infection, we confirmed that the percentage of $\mathrm{CD} 8^{+} \mathrm{T}$ cells in spleen and $\mathrm{mLN}$ were significantly higher in IL-21isoTg mice than WT mice (Figs. 2a and b). The percentage of CD44 ${ }^{+} \mathrm{CD} 62 \mathrm{~L}^{-} \mathrm{CD} 8^{+} \mathrm{T}_{\mathrm{EM}}$ cells and $\mathrm{CD} 44^{-} \mathrm{CD} 62 \mathrm{~L}^{+} \mathrm{CD} 8^{+}$naïve T cells were not different in these organs between WT and IL-21isoTg mice. On the other hand, percentage of $\mathrm{CD}^{+} \mathrm{T}$ cells was lower in $\mathrm{mLN}$ of IL-21 isoTg mice than WT mice. After 10 days of primary infection, lymphocytes were isolated from spleen and $\mathrm{mLN}$. The percentage of $\mathrm{CD}^{+} \mathrm{T}$ cells in these organs of IL-21 isoTg mice was still higher than that of WT mice. Interestingly, the percentage of $\mathrm{CD} 44^{+} \mathrm{CD} 62 \mathrm{~L}^{-} \mathrm{CD} 8^{+} \mathrm{T}_{\mathrm{EM}}$ cells was significantly increased in IL-21 isoTg mice after infection and was considerably higher than that in WT mice. On the other hand, the percentage of $C D 4^{+} T_{E M}$ cells tended to increase after infection in both organs in both mice; however, these changes were not significant.

\section{Discussion}

IL-21 is important to regulate anti-viral $\mathrm{CD}^{+} \mathrm{T}$ cell responses and essential in prolonging antiviral $\mathrm{CD} 8^{+} \mathrm{T}$ cells during chronic viral infection (Elsaesser 2009; Fröhlich 2009; Yi 2009). Signaling of IL-21 with IL-10 help to enhance the development of memory $C D 8^{+} T$ cells via the transcription factor STAT3 (Cui 2011). IL-21 is also important for the production of effector $C D 8^{+} T$ cells (Moretto 2016) and for the highest recall responses of memory CD8 ${ }^{+}$T cells (Yi 2010; Barker 2010; Novy 2011) during specific infections.

The IL-21 isoTg mice express significantly high levels of $\mathrm{CD} 8^{+} \mathrm{T}$ cells. However, these cells are neither effective nor adequate to reduce $L$. monocytogenes primary infection compared to WT mice. Interestingly, we found that $C D 8^{+} T_{E M}$ cells were significantly increased after $L$. monocytogenes primary infection in IL21 isoTg mice compared to WT mice. After secondary challenge infection, the IL-21 isoTg mice exhibited significantly reduced bacterial loads in organs compared to WT mice. It could be possible that the 
significantly high level of $C D 8^{+} T_{E M}$ cells, generated after primary infection, efficiently reduced the bacterial load during secondary infection in IL-21isoTg mice, as reported in certain acute pathogenic infections (Yi 2010; Barker 2010). Factors other than $C D 8^{+} T_{E M}$ cells may also play a role in controlling $L$. monocytogenes infection. Further studies are required to clarify the function of IL-21 in the intracellular bacterial infection. In this study, we demonstrated for the first time that IL-21 and IL-21-induced CD8 ${ }^{+} \mathrm{T}_{\mathrm{EM}}$ cells have an important function for controlling L. monocytogenes infection.

\section{Conclusions}

IL-21 isoTg mouse had similar bacterial load after L. monocytogenes primary infection compared with WT mouse, however, exhibited reduced bacterial load after secondary infection. Because IL-21isoTg mouse induced higher levels of $C D 8^{+} T_{E M}$ cells than WT after primary infection, IL-21-induced CD8 ${ }^{+} T_{E M}$ cells might eventually reduce the bacterial load after secondary challenge infection.

\section{Abbreviations}

IL-21, Interleukin-21; IL-21isoTg, IL-21 isoform transgenic; L. monocytogenes, Listeria monocytogenes; $\mathrm{mLN}$, mesenteric lymph nodes; $\mathrm{T}_{\mathrm{CM}}$, central memory $\mathrm{T}$ cell; $\mathrm{T}_{\mathrm{EM}}$, effector memory $\mathrm{T}$ cell; $\mathrm{WT}$, wild type.

\section{Declarations}

\section{Ethics approval and consent to participate}

We don't use human materials or information.

All mice experiments were performed in accordance with the guidelines of the Laboratory Animal Center of the Yamagata University Faculty of Medicine and were approved by the animal experiment committee of the Yamagata University Faculty of Medicine (approval number: 31005).

\section{Consent to publish}

Not Applicable

\section{Availability of data and materials}

The datasets used and/or analyzed during the current study are available from the corresponding author on reasonable request.

\section{Competing interests}

On behalf of all authors, the corresponding author states that there is no conflict of interest.

\section{Funding}


This work was supported by a grant from the Seizankai medical welfare group. Seizankai medical welfare group provided us with free funding to purchase mice and antibodies and so on.

\section{Authors' Contributions}

MG contributed to the conduct of research and to the writing manuscript, YT, HN, AA and NN contributed to supporting the analysis of data. HA contributed to the management of this study and writing manuscript. All authors are in agreement with the content of this manuscript.

\section{Acknowledgements}

We would like to thank Prof. Dr. D. Heinz and Dr. Joop van den Heuvel (Helmholtz Centre for Infection Research) for the Lmo-InIAm ${ }^{m}$. We would like to thank Dr. Akio Nakane for helpful suggestions for this study. We would like to thank Editage (www.editage.com) for English language editing. This work was supported by a grant from the Seizankai medical welfare group.

\section{References}

Araki A, Nara H, Rahman M, Onoda T, Li J, Juliana FM, et al. (2013) Role of interleukin-21 isoform in dextran sulfate sodium (DSS)- induced colitis, Cytokine 62:262-271. DOI: 10.1016/j.cyto.2013.03.006 Ariotti S, Hogenbirk MA, Dijkgraaf FE, Visser LL, Hoekstra ME, Song JY, et al. (2014) T cell memory: skinresident memory $\mathrm{CD}^{+} \mathrm{T}$ cells trigger a state of tissue-wide pathogen alert. Science 346:101-105. DOI: 10.1126/science. 1254803

Barker BR, Gladstone MN, Gillard GO, Panas MW, Letvin NL. (2010) Critical role for IL-21 in both primary and memory anti-viral CD8+ T-cell responses. Eur J Immunol 40:3085-3096. DOI: 10.1002/eji.200939939

Cui W, Liu Y, Weinstein JS, Craft J, Kaech SM. (2011) An interleukin- 21-interleukin-10-STAT3 pathway is critical for functional maturation of memory CD8 ${ }^{+} \mathrm{T}$ cells. Immunity 35:792-805. DOI:

10.1016/j.immuni.2011.09.017

Elsaesser H, Sauer K, Brooks DG. (2009) IL-21 is required to control chronic viral infection. Science 324:1569-1572. DOI: 10.1126/science. 1174182

Fröhlich A, Kisielow J, Schmitz I, Freigang S, Shamshiev AT, Weber J, et al. (2009) IL-21R on T cells is critical for sustained functionality and control of chronic viral infection. Science 324:1576-1580. DOI: 10.1126/science.1172815

Gebhardt T, Wakim LM, Eidsmo L, Reading PC, Heath WR, Carbone FR. (2009) Memory T cells in nonlymphoid tissue that provide enhanced local immunity during infection with herpes simplex virus. Nat Immuno/ 10:524-530. DOI: 10.1038/ni.1718 
Hansen SG, Ford JC, Lewis MS, Ventura AB, Hughes CM, CoyneJohnson L, et al. (2011) Profound early control of highly pathogenic SIV by an effector memory T-cell vaccine. Nature 473:523-527. DOI: 10.1038/nature10003

Hansen SG, Piatak MJr, Ventura AB, Hughes CM, Gilbride RM, Ford JC, et al. (2013) Immune clearance of highly pathogenic SIV infection. Nature 502:100-104. DOI: 10.1038/nature22984

Hansen SG, Vieville C, Whizin N, Coyne-Johnson L, Siess DC, Drummond DD, et al. (2009) Effector memory $T$ cell responses are associated with protection of rhesus monkeys from mucosal simian immunodeficiency virus challenge. Nat Med 15:293-299. DOI: 10.1038/nm.1935

Hinrichs CS, Spolski R, Paulos CM, Gattinoni L, Kerstann KW, Palmer DC, et al. (2008) IL-2 and IL-21 confer opposing differentiation programs to $\mathrm{CD}^{+} \mathrm{T}$ cells for adoptive immunotherapy. Blood 111:53265333. DOI: 10.1182/blood-2007-09-113050

lijima N, Iwasaki A. (2014) T cell memory: a local macrophage chemokine network sustains protective tissue-resident memory CD4 T cells. Science 346:93-98. DOI: 10.1126/science.1257530

Kaech SM, Cui W. (2012) Transcriptional control of effector and memory CD8 ${ }^{+} \mathrm{T}$ cell differentiation. Nat Rev Immuno/ 12:749-761. DOI: 10.1038/nri3307

Masopust D, Vezys V, Marzo AL, Lefrancois L. (2001) Preferential localization of effector memory cells in nonlymphoid tissue. Science 291:2413-2417. DOI: 10.1126/science.1058867

Moretto MM, Khan IA. (2016) IL-21 is important for induction of KLRG1+ effector CD8 T cells during acute intracellular infection. J Immuno/ 196:375-384. DOI: 10.4049/jimmunol.1501258

Mueller SN, Gebhardt T, Carbone FR, Heath WR. (2013) Memory T cell subsets, migration patterns, and tissue residence. Annu Rev Immuno/31:137-161. DOI: 10.1146/annurev-immunol-032712-095954

Nara H, Rahman M, Araki A, Jin L, Takeda Y, Asao H. (2013) IL-21 isoform is a membrane-bound ligand and activates directly interacted cells. Cytokine 61:656-663. DOI: 10.1016/j.cyto.2012.12.010

Novy P, Huang X, Leonard WJ, Yang Y. (2011) Intrinsic IL-21 signaling is critical for CD8 T cell survival and memory formation in response to vaccinia viral infection. $J$ Immunol 186:2729-2738. DOI: 10.4049/jimmunol.1003009

Parrish-Novak J, Dillon SR, Nelson A, Hammond A, Sprecher C, Gross JA, et al. (2000) Interleukin 21 and its receptor are involved in NK cell expansion and regulation of lymphocyte function. Nature 408:57-63. DOI: $10.1038 / 35040504$

Rahman M, Nara H, Onoda T, Araki A, Li J, Hoshino T, et al. (2007) Cloning and characterization of an isoform of interleukin-21. FEBS Lett 581:4001-4009. DOI: 10.1016/j.febslet.2007.07.034 
Reyes-Sandoval A, Wyllie DH, Bauza K, Milicic A, Forbes EK, Rollier CS, et al. (2011) CD8 ${ }^{+}$T effector memory cells protect against liver-stage malaria. J Immunol 187:1347-1357. DOI: 10.4049/jimmunol.1100302

Sallusto F, Lenig D, Förster R, Lipp M, Lanzavecchia A. (1999) Two subsets of memory T lymphocytes with distinct homing potentials and effector functions. Nature 401:708-712. DOI: 10.1038/44385

Sheridan BS, Pham QM, Lee YT, Cauley LS, Puddington L, Lefrancois L. (2014) Oral infection drives a distinct population of intestinal resident memory $\mathrm{CD}^{+} \mathrm{T}$ cells with enhanced protective function. Immunity 40:747-757. DOI: 10.1016/j.immuni.2014.03.007

Spolski R, Leonard WJ. (2008) Interleukin-21: basic biology and implications for cancer and autoimmunity. Annu Rev Immunol 26:57-79. DOI: 10.1146/annurev.immunol.26.021607.090316

Spolski R, Leonard WJ. (2014) Interleukin-21: a double-edged sword with therapeutic potential. Nat Rev Drug Discov 13:379-395. DOI: 10.1038/nrd4296

Wherry EJ, Teichgräber V, Becker TC, Masopust D, Kaech SM, Antia R, et al. von Andrian U.H., Ahmed R. (2003) Lineage relationship and protective immunity of memory CD8 T cell subsets. Nat Immunol 4:225234. DOI: $10.1038 /$ ni889

Wollert T, Pasche B, Rochon M, Deppenmeier S, van den Heuvel J, Gruber AD, et al. (2007) Extending the host range of Listeria monocytogenes by rational protein design. Cel/ 129:891-902. DOI:

10.1016/j.cell.2007.03.049

Yi JS, Du M, Zajac AJ. (2009) A vital role for interleukin-21 in the control of a chronic viral infection. Science 324:1572-1576. DOI: 10.1126/science.1175194

Yi JS, Ingram JT, Zajac AJ. (2010) IL-21 deficiency influences CD8 T cell quality and recall responses following an acute viral infection. J Immunol 185:4835-4845. DOI: 10.4049/jimmunol.1001032

Zeng R, Spolski R, Finkelstein SR, Oh S, Kovanen PE, Hinrichs CS, et al. (2005) Synergy of IL-21 and IL-15 in regulating $\mathrm{CD}^{+} \mathrm{T}$ cell expansion and function. J Exp Med 201:139-148. DOI: 10.1084/jem.20041057

\section{Figures}


a

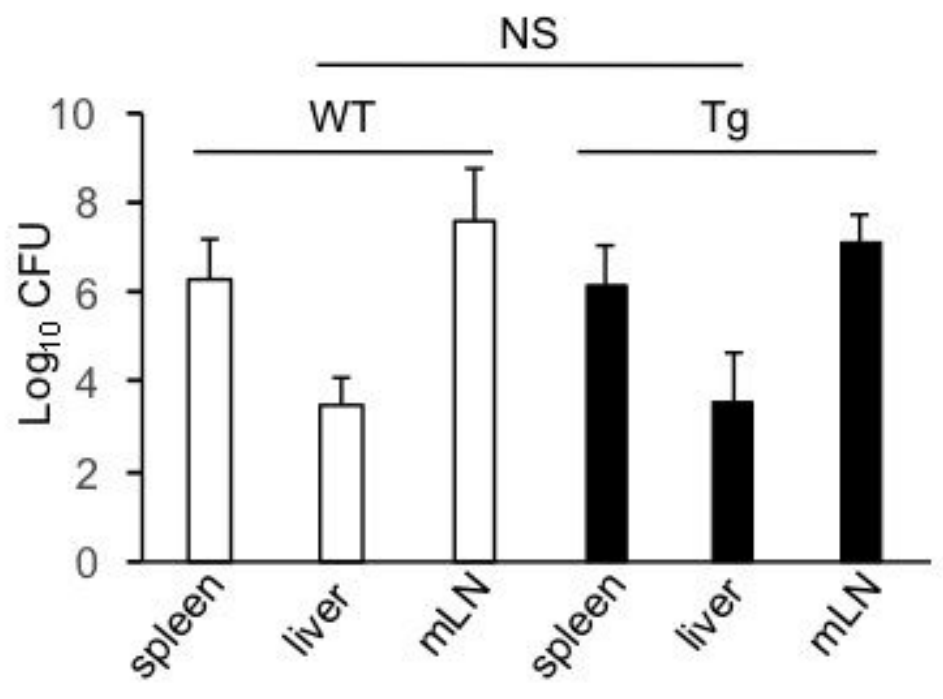

b

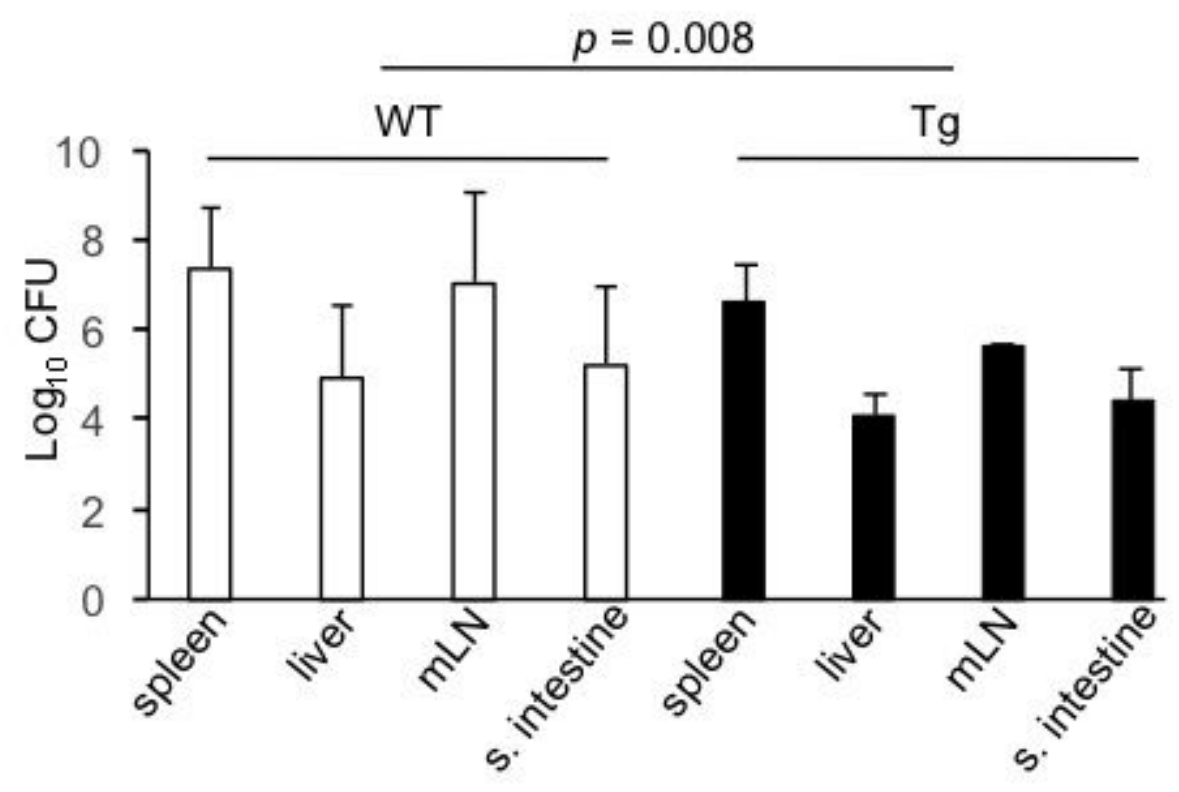

Figure 1

IL-21isoTg mice exhibited reduced bacterial load after L. monocytogenes challenge infection Bacterial loads of each organ after primary (a) and secondary infection (b) are shown. Values are represented as mean \pm SD. Data were analyzed by two-way ANOVA with Bonferroni post hoc test where $p<0.05$ is statistically significant. NS: not significant. $n=5$ for WT and $n=7$ for Tg in primary infection (a) and $n=7-10$ for WT and $n=5-9$ for Tg in secondary infection (b) 
a
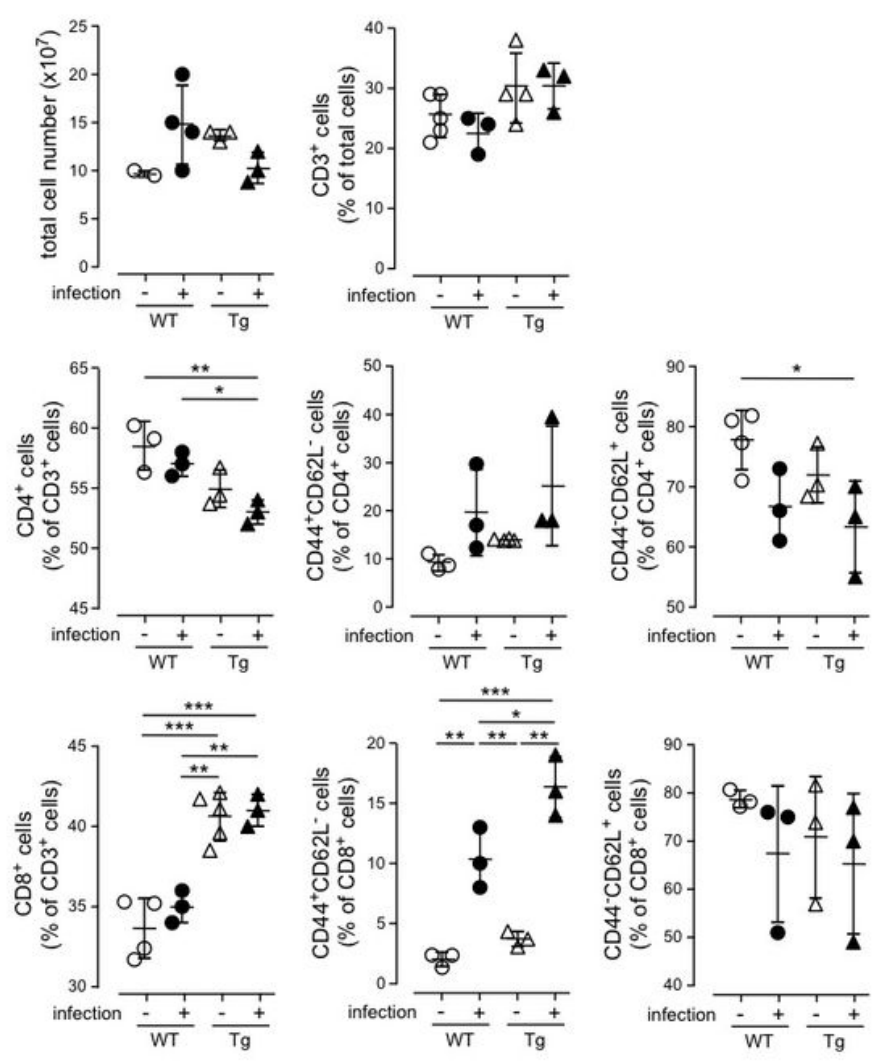

spleen

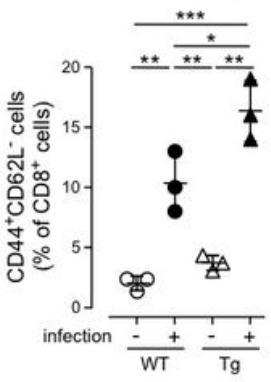

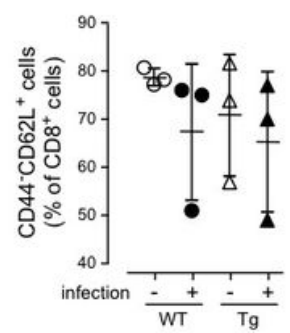

b

$\mathrm{mLN}$
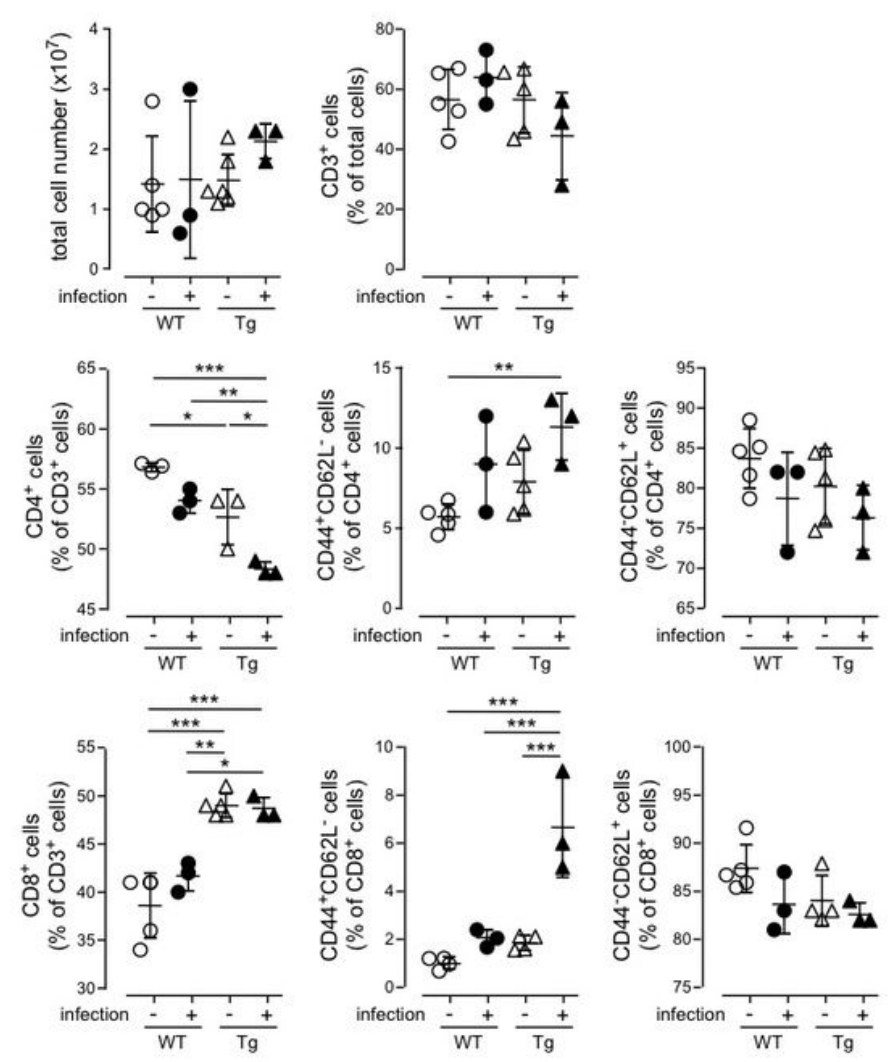

Figure 2

IL-21isoTg mice express high numbers of CD8+ TEM cells after L. monocytogenes infection IL-21isoTg and WT mice were sacrificed before and 10 days after $\mathrm{L}$. monocytogenes infection. Spleen (a) and $\mathrm{mLN}$ (b) were collected and cells were stained for detecting the expression of lymphocyte markers. Scatter plots showing the total cell number or percentage of each cell population. Data were analyzed by one-

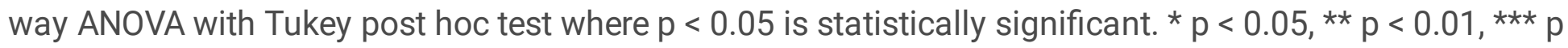
$<0.001$. $n=3-5$ for WT and for Tg

\section{Supplementary Files}

This is a list of supplementary files associated with this preprint. Click to download.

- NC3RsARRIVEGuidelinesChecklistfillable.pdf 